\title{
SURROGATE MODELLING OF LIQUID STORAGE TANKS FOR SEISMIC PERFORMANCE DESIGN AND ASSESSMENT
}

\author{
Konstantinos Bakalis $^{1}$, Michalis Fragiadakis ${ }^{2}$, and Dimitrios Vamvatsikos ${ }^{3}$ \\ ${ }^{1}$ National Technical University of Athens \\ Institute of Steel Structures \\ Zografou Campus, 9 Iroon Polytechneiou str, 15780 Zografou, Athens, Greece \\ e-mail: kbakalis@mail.ntua.gr \\ ${ }^{2}$ National Technical University of Athens \\ Laboratory for Earthquake Engineering \\ Zografou Campus, 9 Iroon Polytechneiou str, 15780 Zografou, Athens, Greece \\ e-mail: $\underline{\text { mfrag@mail.ntua.gr }}$ \\ ${ }^{3}$ National Technical University of Athens \\ Institute of Steel Structures \\ Zografou Campus, 9 Iroon Polytechneiou str, 15780 Zografou, Athens, Greece \\ e-mail: divamva@mail.ntua.gr
}

Keywords: Instructions, ECCOMAS Thematic Conference, Structural Dynamics, Earthquake Engineering, Proceedings.

\begin{abstract}
The finite element method (FEM) is often employed to create detailed models for the seismic assessment and design of liquid storage tanks. This comprehensive approach offers accuracy, which is counter-balanced however by its computational inefficiency, especially for the case of large-scale engineering problems. Regardless of the continuous evolution of computer technology, surrogate models are necessary when such problems of engineering practice are encountered. This study, attempts to develop an appropriate surrogate modelling approach, tailored for the design and seismic risk assessment of liquid storage tanks. A formulation that disregards fluid-structure-interaction is employed in view of providing a reasonable compromise between modelling complexity and error. At the same time, a simplified methodology based on nonlinear static procedures is proposed for the assessment of atmospheric tanks. The comparison with Incremental Dynamic Analysis reveals a reasonable, yet conservative in some cases, match for the damage states considered, thus offering an alternative methodology that may easily be incorporated within code-based provisions.
\end{abstract}




\section{INTRODUCTION}

Large-capacity cylindrical tanks are widely used to store a variety of liquids, such as petroleum and liquefied natural gas. The seismic risk of such industrial facilities is considerably higher compared to ordinary structures, since the damage induced by a strong ground motion may trigger uncontrollable consequences, not only on the actual facility but also on the environment. Recent earthquakes, e.g., Kocaeli (1999) and Tohoku (2011), have shown that heavy damage on tanks may lead to temporary loss of essential facilities, usually followed by leakage and/or fire. In order to meet a desired level of safety, Performance-Based-Earthquake-Engineering (PBEE) concepts can be employed to account for any potential sources of uncertainty. However, recent codes of practice have not fully adopted the PBEE concept, and its application to industrial facilities is limited to simple code provisions.

\section{PROBLEM DEFINITION}

Recent earthquakes have highlighted the need for innovative engineering concepts in order to mitigate the devastating consequences following a strong ground motion. Although extensive research takes place to date, earthquakes remain a major threat to the community both from a social and a financial point of view. The PBEE concept forms the state-of-the-art approach for evaluating the seismic risk, and should also be extended to critical infrastructure, such as the liquid storage tanks found in industrial complexes. Various approaches serve under this framework, ranging from simplified deterministic to comprehensive probabilistic. In the latter case, the structural model adopted constitutes a key parameter for the successful performance evaluation, due to the computational time required during the analysis. This remark is highlighted for the case of atmospheric liquid storage tanks, where the simulation of the fluid-structureinteraction may result in complex finite element models (FEM) that require a considerable amount of time even for a single dynamic analysis [1]. Similar studies have developed numerical approximations for the contained liquid [2,3], in an attempt to minimise the estimated computational time. Although the aforementioned FEM-based procedures may be able to capture complex modes of failure (e.g. local buckling), their suitability within a probabilistic framework may become computationally prohibitive. Still, at least two studies have attempted to develop simplified simulation techniques that blend efficiency and accuracy. Malhotra and Veletsos [46] presented a simplified model for the two-dimensional (2D) analysis of liquid storage tanks, while Cortes et al. [7] developed a model based on rigid beams and equivalent springs that can be used for rapid dynamic analysis. Still, neither of the two models can be easily applied outof-the-box with commercial software: The first approach is based on custom-made analysis software, while the second needs to be calibrated with a detailed finite element model (originally taken from the NZEE standards [8] by the authors).

\section{MODELLING OF LIQUID STORAGE TANKS}

The response of liquid storage tanks can be idealised using a two-degree-of-freedom (2DOF) system, where the two masses (impulsive and convective) are considered decoupled [9-11]. The geometric and modal characteristics of the hydrodynamic problem are determined using equivalent parameters for the impulsive and convective masses. For the purpose of this study, the recommendations of Eurocode 8 [12] are adopted featuring Part 4 [13], where the design of tanks is discussed in detail. Under the assumption that the impulsive pressure is acting on the tank walls only, estimates for parameters such as the natural period coefficients $\left(C_{i}\right.$ and $\left.C_{c}\right)$, the masses $\left(m_{i}\right.$ and $\left.m_{c}\right)$ and the effective height components $\left(h_{i}\right.$ and $\left.h_{c}\right)$ are obtained. Subscripts " $i$ " and " $c$ " are used to denote "impulsive" and "convective" respectively. Previous studies have shown that the contribution of the convective mass to the overall response of the structure can 
be ignored, as the impulsive mass is held responsible for the majority of the damage that tanks suffer during a strong ground motion event $[2,14]$.

A simplified modelling methodology for liquid storage tanks was recently proposed by Bakalis et al. [15]. The surrogate modelling approach offers a compromise between computational efficiency and accuracy for the nonlinear static or dynamic analysis. It is based on the work of Malhotra and Veletsos [6] for liquid storage systems, where the uplifting mechanism of unanchored tanks is modelled analytically. According to the modelling procedure adopted the base plate is divided into an even number of strips and one of them is subjected to an incremental uplifting static load $(V)$ in order to determine the associated resistance (Figure 1). The strip model consists of force-based fibre beam column elements with element length equal to approximately 15 times the base plate thickness, $t_{b}$. A uniaxial elastoplastic material is assigned to the fibres in order to capture the inelastic behaviour of the base plate during uplift. Geometric nonlinearities are taken into account through the co-rotational formulation. The foundation of the tank is modelled using Winkler springs to account for the soil (or concrete slab) stiffness beneath the plate. The Winkler springs are also assigned an elastic-no-tension material which is suitable for the simulation of the base plate uplift. The base plate itself is modelled using rigid beams that are supported on elastic multilinear springs. The latter simulate the nonlinear uplifting resistance for each of the ' $N$ ' beam-spokes, representing equal-area sectors of the circular base plate. One may notice that the convective component of the fluid is not considered in the model. This decision is twofold. Obviously, the contribution of the long-period convective component to the rigid-impulsive response of a broad tank may be deemed negligible [2]. That essentially provides a single rather than a double degree-of-freedom (DOF) system, the efficiency of which can only be appreciated within a probabilistic framework. As a result, the impulsive mass $\left(m_{i}\right)$ of the system is connected to the base using the elastic element shown in Figure 2(a). The deflected shape shown in Figure 2(b) presents the uplifting mechanism of the tank, where the base shear $\left(V_{b}\right)$ induces a certain amount of uplift $(w)$ on the beam-spokes of the model. This mechanism offers the ability to estimate all major modes of failure, when they are expressed as a function of uplift. Sloshing response on the other hand is only affected by parameters such as the convective mass of the fluid and the available freeboard, and may be calculated though a simple response spectrum analysis for the convective component, following the Eurocode 8 [13] provisions. 

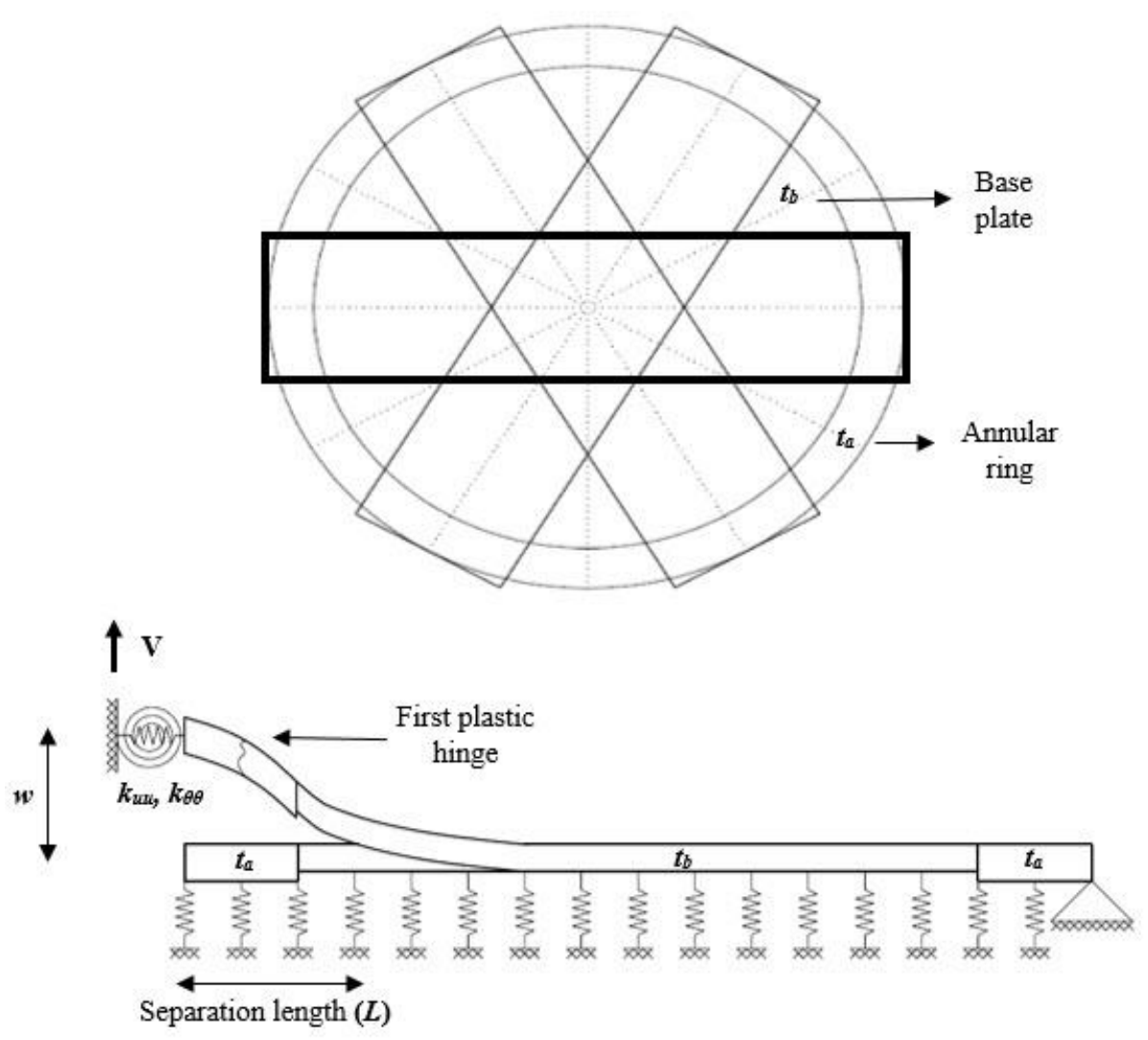

Figure 1: Strip model explained.
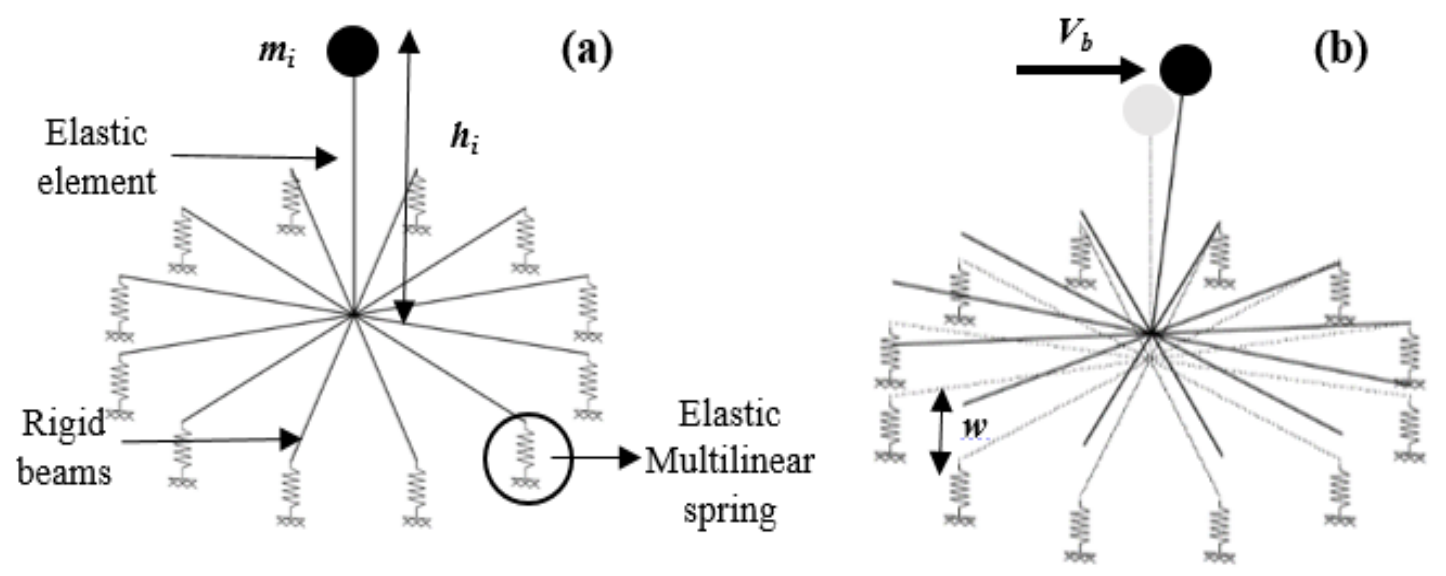

Figure 2: (a) Tank model and (b) its deflected shape.

\subsection{Case Study}

As a case study the liquid storage tank with the following geometric characteristics is adopted. The tank considered has a radius $(R)$ equal to $13.9 \mathrm{~m}$ and a total height $\left(h_{t}\right)$ of $16.5 \mathrm{~m}$. The bottom course wall $\left(t_{w}\right)$ is $17.7 \mathrm{~mm}$ thick, while the corresponding base plate $\left(t_{b}\right)$ and annular ring $\left(t_{a}\right)$ thickness are $6.4 \mathrm{~mm}$ and $8.0 \mathrm{~mm}$, respectively. The fluid stored in the tank is assumed to reach the maximum allowable fluid height of $h_{f}=14 \mathrm{~m}$, resulting to a 'fluid height over radius' ratio $\left(h_{f} / R\right)$ equal to 1.01 . The properties of the liquid storage system adopted are summarised on Table 1. 
Table 1. Properties of the tank examined.

\begin{tabular}{lccc}
\hline & Variable description & Notation (units) & Numerical values \\
\hline & Radius & $R_{t}(\mathrm{~m})$ & 13.9 \\
& Height & $h_{t}(\mathrm{~m})$ & 16.5 \\
& Wall thickness per course & $t_{w}(\mathrm{~mm})$ & $17.7 / 15.7 / 13.7 / 11.7 / 9.7 / 7.8 / 6.4 / 6.4 / 6.4$ \\
Tank properties & Base plate thickness & $t_{b}(\mathrm{~mm})$ & 6.4 \\
& Annular ring thickness & $t_{a}(\mathrm{~mm})$ & 8.0 \\
& Roof mass & $m_{r}(\mathrm{ton})$ & 35 \\
& Yield strength & $f_{y}(\mathrm{MPa})$ & 235 \\
& Steel Young's Modulus & $E_{s}(\mathrm{GPa})$ & 210 \\
\hline \multirow{2}{*}{ Fluid properties } & Height & $h_{f}(\mathrm{~m})$ & 14.0 \\
& Density & $p_{f}\left(\mathrm{~kg} / \mathrm{m}^{3}\right)$ & 1000 \\
\hline
\end{tabular}

\subsection{Validation}

Figure 3 presents a comparison of the overturning moment obtained with our model and with the detailed finite element model of Vathi et al. [2]. Good agreement between the two curves is observed, despite the discrepancies found in the post yield zone. The modelling procedure developed herein presents a practically perfect match close to the yield point, although it seems to underestimate the response of the unanchored tank for larger deformations. In all, the modelling procedure adopted provides a good match to the FEM solution, as the differences found do not exceed $15 \%$.

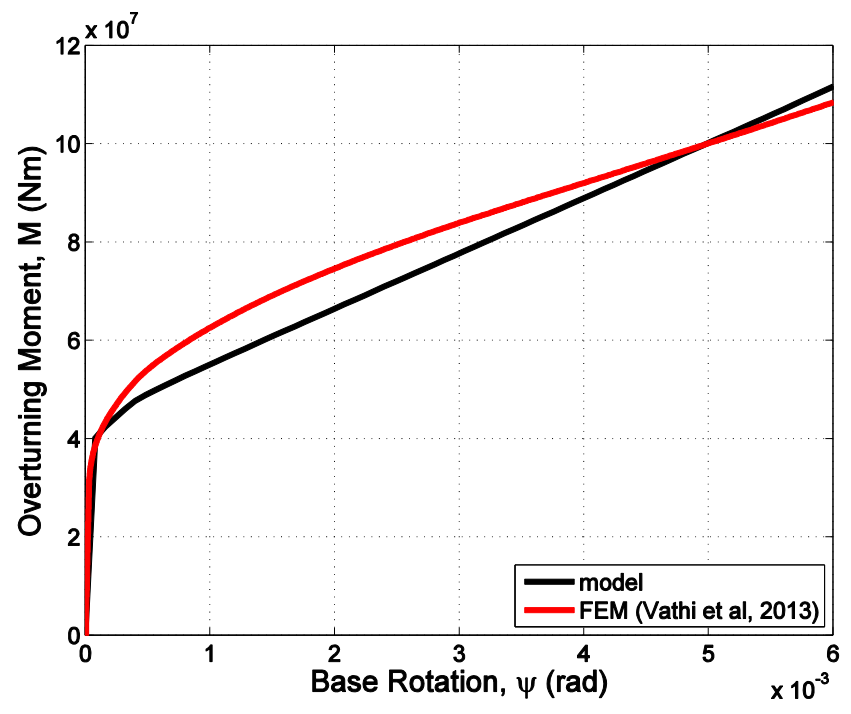

Figure 3. Base plate rotational resistance.

\section{PERFORMANCE OBJECTIVES}

Field investigations after major earthquakes have revealed a variety of failure modes on atmospheric tanks. They may be summarised to shell buckling, base sliding and sloshing damage to the upper tank shell and roof. EC8-part 4 [13] provides special provisions for these modes of failure, as shown by Vathi et al. [2]. For instance, when partial uplift is allowed, either for design purposes or due to poor detailing of the anchors, the rotation of the plastic hinge developed on the base plate of the tank should not exceed a certain rotational capacity. Moreover, the excitation of the long period convective mass may cause sloshing of the contained liquid, 
which can in turn damage the upper parts of the tank (roof, upper wall course). During strong ground motion events, hydrostatic and hydrodynamic effects may lead to high internal pressure on the tank walls. Overturning for those thin shell structures is resisted by compressive meridional stresses on the wall. Although high pressure may increase the capacity against buckling by introducing high hoop stress, local yielding may trigger an elastic-plastic buckling failure around the lower course of the tank's perimeter, known as the "Elephant's Foot Buckling".

The most damaging failure modes are mainly associated with plate/shell rupture, as they may result in loss of the contained liquid. Rupturing either the bottom layers of the tank wall or the base plate is expected to trigger uncontrolled loss of the stored material, with all the associated consequences considered. Recently, Bakalis et al. [16] developed a performance-based assessment methodology for atmospheric steel liquid storage tanks. The PBEE framework considers three damage states of increasing severity, namely minor (DS1), severe without leakage (DS2) and loss of containment (DS3). Although this classification may seem reasonable for roughly understanding the extent of damage, the accurate assessment of loss may become tricky as, for example, the different mechanisms involved in a single damage state may be associated with varying degrees of component damage. For instance, the sloshing height response represents relatively easy-to-repair damage at the top of the tank, compared to an exceedance of a plastic rotation limit at the base. Thus, it becomes more informative to also classify damage based on the actual component that has failed. Figure 4 presents the associated failure modes on the median Incremental Dynamic Analysis (IDA) curve [17] for the unanchored liquid storage tank considered. The FEMA P695 [18] far field ground motion set is used for the nonlinear dynamic analysis. The base uplift is adopted as one of the Engineering Demand Parameters (EDP) and the impulsive period spectral acceleration $S_{\mathrm{a}}\left(T_{i m p}\right)$ or the peak ground acceleration PGA (similar due to low $T_{\text {imp }}$ ) are employed as suitable Intensity Measures (IM) that adequately capture the response of a liquid storage system. It is evident that a component-based classification of damage is quite informative, where the upper course of the tank ( $\mathrm{SL}=$ sloshing), its lower course $(\mathrm{EFB})$, the base plate $\left(\theta_{\mathrm{pl}}=\right.$ plastic rotation), and the anchors $(\mathrm{AN}=\mathrm{yielding} /$ fracture of anchors) are individually examined. Failure modes such as buckling and plastic rotation are revealed during the nonlinear time-history analysis. Sloshing damage at the top of the tank wall is also considered. Still, as shown in Figure 4, this may only appear at excessive spectral acceleration values for large tanks due to the ultra-long convective period $\left(T_{c o n}\right)$.

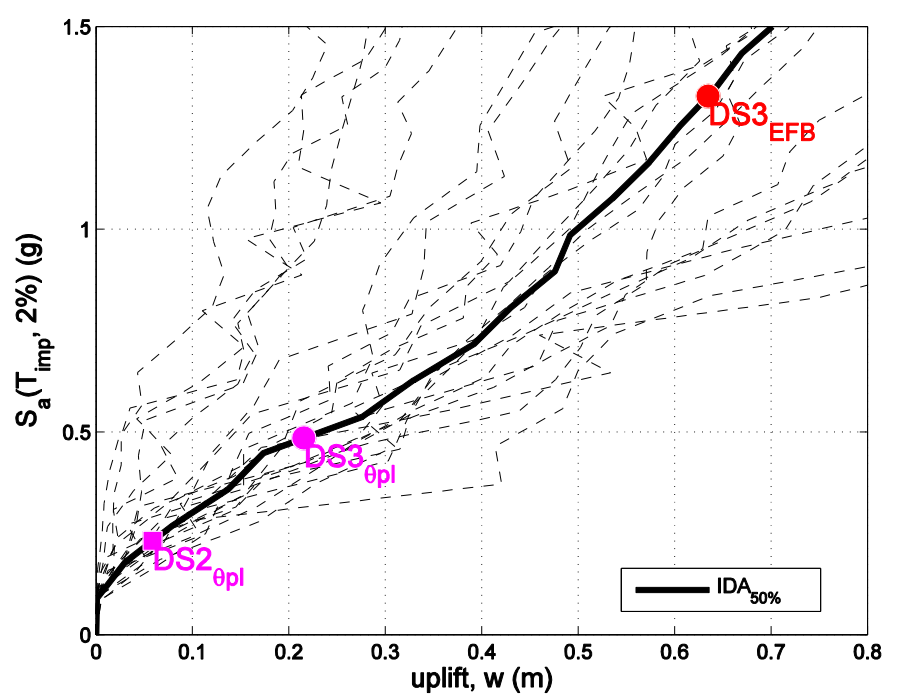

Figure 4: Single record and median IDA curves for the unanchored tank examined. Sloshing damage appears well beyond the limits of the graph. 
The local performance objectives summarised in Table 2 may indeed offer a comprehensive procedure for understanding the extent of damage on a liquid storage unit, even offering the potential for assigning detailed repair cost estimates. However, it may often be the case that a global classification is required, suitable for characterising one or more tanks without specific reference to the component that has been damaged. In that sense, DS1 represents minor damage induced by a sloshing wave height of the contained liquid equal to the freeboard. DS2 refers to severe damage at any component of the tank without leakage, where the exceedance of either a sloshing wave height equal to 1.4 times the available freeboard or a plastic rotation of $0.2 \mathrm{rad}$ at the base plate triggers the damage state violation. DS3, finally, provides information on the loss of containment through the exceedance of either the axial EFB capacity $\left(\mathrm{N}_{\mathrm{EFB}}\right)$ or the base plate plastic rotation of $0.4 \mathrm{rad}$. As far as anchored systems are concerned, the yielding of the anchors is considered for DS1, while the fracture of the connection for DS2. Global performance objectives are presented on Table 3.

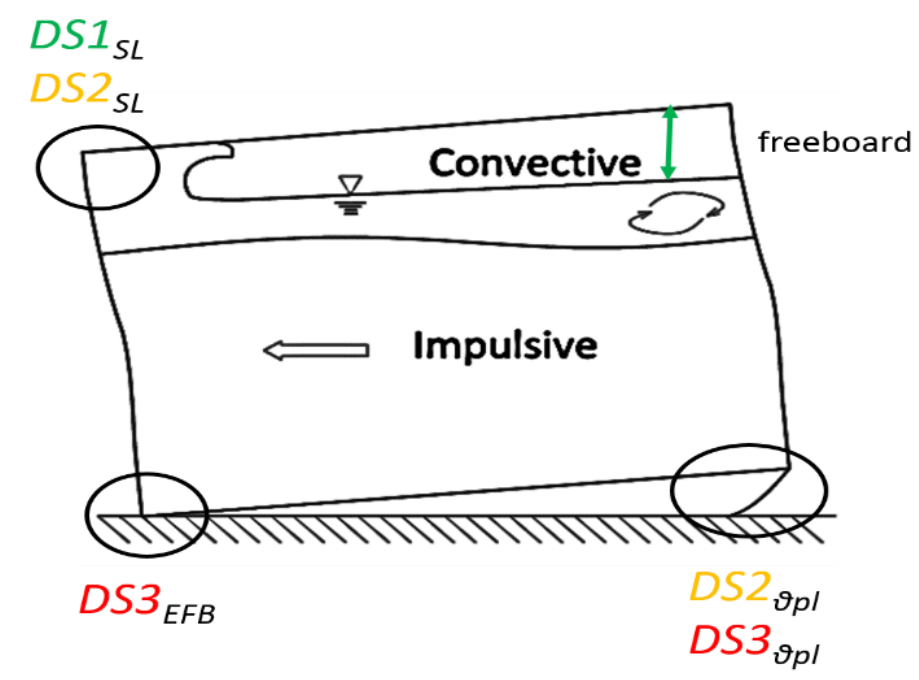

Figure 5: Global versus Local performance objectives for unanchored tanks.

Table 2: Local performance objectives.

\begin{tabular}{c|c}
\hline Local DSi & DS Capacities \\
\hline $\mathrm{DS} 1_{\mathrm{SL}}$ & freeboard \\
$\mathrm{DS} 1_{\mathrm{AN}}$ & Anchorage yielding \\
$\mathrm{DS} 2_{\mathrm{SL}}$ & $1.4^{*}$ freeboard \\
$\mathrm{DS} 2_{\mathrm{AN}}$ & Anchorage fracture \\
$\mathrm{DS} 2_{\theta \mathrm{pl}}$ & $0.2 \mathrm{rad}$ \\
$\mathrm{DS} 3_{\mathrm{pl}}$ & $0.4 \mathrm{rad}$ \\
$\mathrm{DS} 3_{\mathrm{EFB}}$ & EFB strength \\
\hline
\end{tabular}


Table 3: Global performance objectives

\begin{tabular}{ccc}
\hline Tank Description & Global (DSi) & DS Capacities \\
\hline \multirow{3}{*}{ Unanchored } & $\mathrm{DS} 1$ & $\mathrm{DS} 1_{\mathrm{SL}}$ \\
& $\mathrm{DS} 2$ & $\mathrm{DS} 2_{\mathrm{SL}}$ or DS2 $2_{\theta \mathrm{pl}}$ \\
& $\mathrm{DS} 3$ & $\mathrm{DS} 3_{\theta \mathrm{pl}}$ or DS3 $3_{\mathrm{EFB}}$ \\
\hline \multirow{3}{*}{ Anchored } & $\mathrm{DS} 1$ & $\mathrm{DS} 1_{\mathrm{SL}}$ or DS1 $1_{\mathrm{AN}}$ \\
& $\mathrm{DS} 2$ & $\mathrm{DS} 2_{\mathrm{SL}}$ or DS $2_{\mathrm{AN}}$ or DS2 $2_{\theta \mathrm{pl}}$ \\
& $\mathrm{DS} 3$ & $\mathrm{DS} 3_{\theta \mathrm{pl}}$ or DS3 $3_{\mathrm{EFB}}$ \\
\hline
\end{tabular}

\section{SIMPLIFIED INELASTIC RESPONSE FOR LIQUID STORAGE TANKS}

Performance objectives may be well defined, however, their application within a code-based methodology is still out of the box without the enforcement of nonlinear dynamic analysis. From the early days of earthquake engineering [19] till the development of more sophisticated methods [20-22], several research efforts exist for the prediction of inelastic response of structures. In spite of the miscellaneous approaches developed to date, there is common ground related to the translation of complex engineering concepts to simpler solutions that are more appropriate for practicing engineers. In that sense, the Static Pushover analysis (SPO) plays an important role in the assessment as well as the design of structures, where the well-known reduction factor $(R)$-ductility $(\mu)$-period $(T)$ relationship is required to determine the nonlinear response of the equivalent SDOF oscillator. Such relationships are available for a variety of structural systems (see Ruiz-Garcia and Miranda [21] for elastoplastic systems, Vamvatsikos and Cornell [20] for oscillators with complex quadrilinear backbones). Malhotra and Veletsos [6] have already shown that liquid storage tanks develop a nonlinear-elastic response with postyield hardening behaviour. Unfortunately, to the authors' knowledge, such $R-\mu-T$ relationships are not available in the existing literature, while Malhotra and Veletsos chose to use instead an equivalent linearization technique that was also calibrated for elastoplastic systems. Left alone with an 'accuracy versus rapidness' dilemma, the generation of new relationships that correspond to the system examined is preferred over an obscure approximation that is based on existing $R-\mu-T$ relationships.

\subsection{Fitting the hardening branch}

A SDOF model with a bilinear backbone and a hardening ratio $a_{h}=1 \%$ is used to simulate the response for a wide range of periods $(0.1-1 \mathrm{sec})$. A series of Incremental Dynamic Analyses is performed for the given periods in order to form a set of data that will allow the fitting of the hardening branch response. A pattern in log-space is adopted for the regression of the $\mu \mid \mathrm{R}$ set of data, as shown in Eq. (1). A pattern in the form of Eq. (2) is adopted for the regression of the Eq. (1) coefficients $\left(\beta i_{x} \%\right)$ versus the system period. The entire fitting procedure is presented below, where Figure 6 depicts the IDA curves and Figure 7 the Eq. (1) coefficient fits. Table 4 summarises the results of the fitting procedure.

$$
\begin{gathered}
\ln \mu_{x \%}=\beta_{0, x \%}+\beta_{1, x \%} \ln R+\beta_{2, x \%}(\ln R)^{1.5} \\
\beta_{i, x \%}=b_{1, x \%}+b_{2, x \%} T+b_{3, x \%}(1 / T)
\end{gathered}
$$




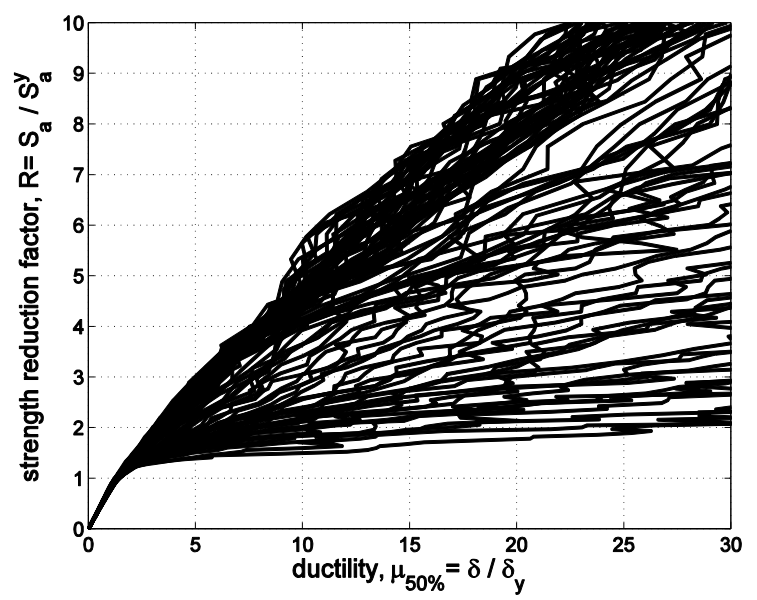

Figure 6. Strength reduction factor versus median ductility for $\mathrm{T}=0.1-1 \mathrm{sec}$.
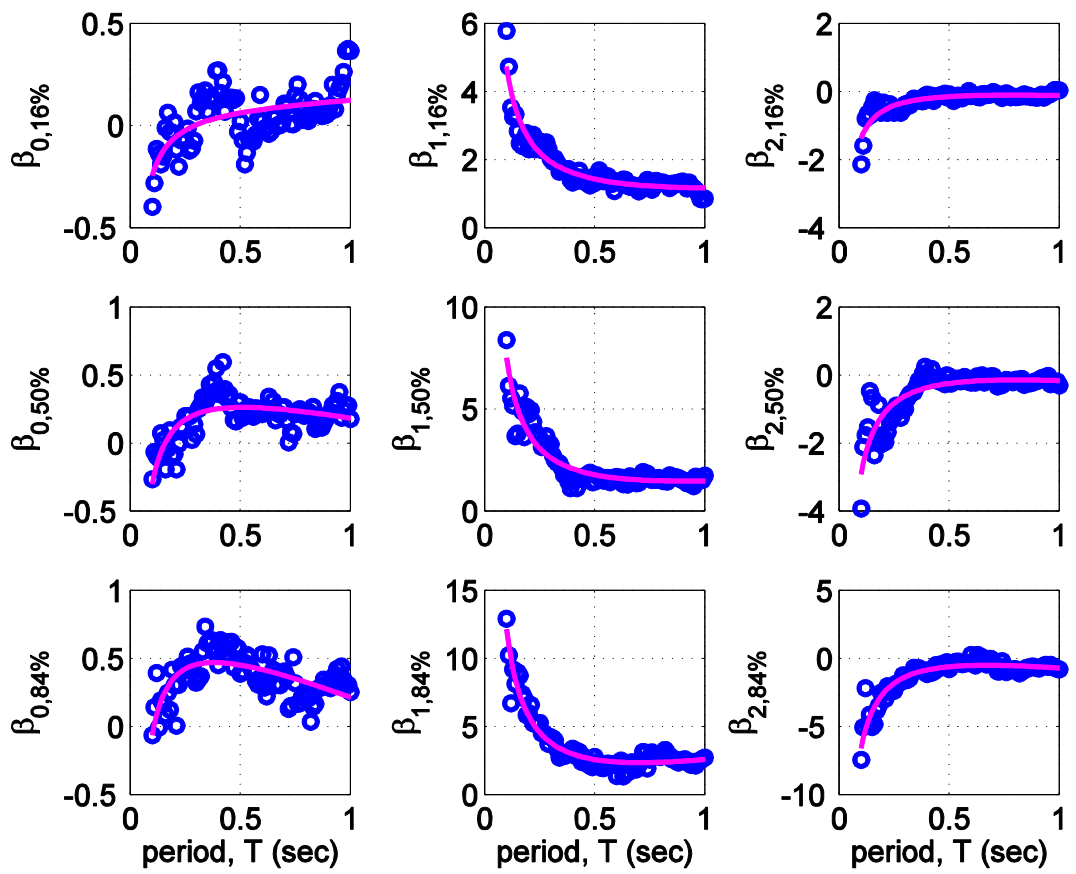

Figure 7: Regression on the Eq. (1) coefficients.

Table 4: Coefficients and functions for the IDA hardening branch fit.

\begin{tabular}{|c|c|c|c|c|c|c|c|c|c|}
\hline \multirow[b]{2}{*}{ hardening } & \multicolumn{3}{|c|}{$b i_{x} \%$ for $\beta_{0, x \%}$} & \multicolumn{3}{|c|}{$b i_{x} \%$ for $\beta_{1, x \%}$} & \multicolumn{3}{|c|}{$b i_{x \%}$ for $\beta_{2, x} \%$} \\
\hline & $16 \%$ & $50 \%$ & $84 \%$ & $16 \%$ & $50 \%$ & $84 \%$ & $16 \%$ & $50 \%$ & $84 \%$ \\
\hline 1 & 0.1056 & 0.6032 & 0.9851 & 0.4134 & -0.2010 & -1.4072 & 0.3221 & 0.7521 & 2.0113 \\
\hline$T$ & 0.0551 & -0.3320 & -0.6725 & 0.3290 & 0.9319 & 2.6714 & -0.26667 & -0.5504 & -1.8568 \\
\hline $1 / T$ & -0.0354 & -0.0868 & -0.0979 & 0.4275 & 0.7613 & 1.3283 & -0.1659 & -0.3598 & -0.8404 \\
\hline
\end{tabular}

\section{FRAGILITY CURVES BASED ON STATIC PUSHOVER ANALYSIS}

Several methodologies for estimating fragility curves have been proposed based on nonlinear static procedures. The Static Pushover analysis is often employed to evaluate the system performance in view of the simplicity offered to practicing engineers. Despite the approximating nature of the method, there is a major drawback related to record-to-record variability which 
is in turn propagated to the seismic fragility estimation. Thus, an inherently probabilistic problem is treated in a deterministic way, simply due to pushover analysis. Using the aforementioned expressions, record-to-record variability can be incorporated explicitly, while limit-state capacity uncertainties can also be included for a structural system that can adequately be approximated by a SDOF oscillator. The aforementioned procedure finds application for the case of liquid storage tanks when a model similar to the one developed by Bakalis et al. $[15,16]$ is used. Following a Static Pushover analysis performed on the full tank model, a bilinear idealisation of the system's performance is necessary to obtain the yield point $\left(\delta_{y}, V_{b y}\right)$. Figure 8 presents the impulsive mass displacement (here noted as $\delta_{\text {roof }}$ for compatibility reasons with the pushover terminology) versus the horizontal force (i.e. base shear) $V_{b}$.

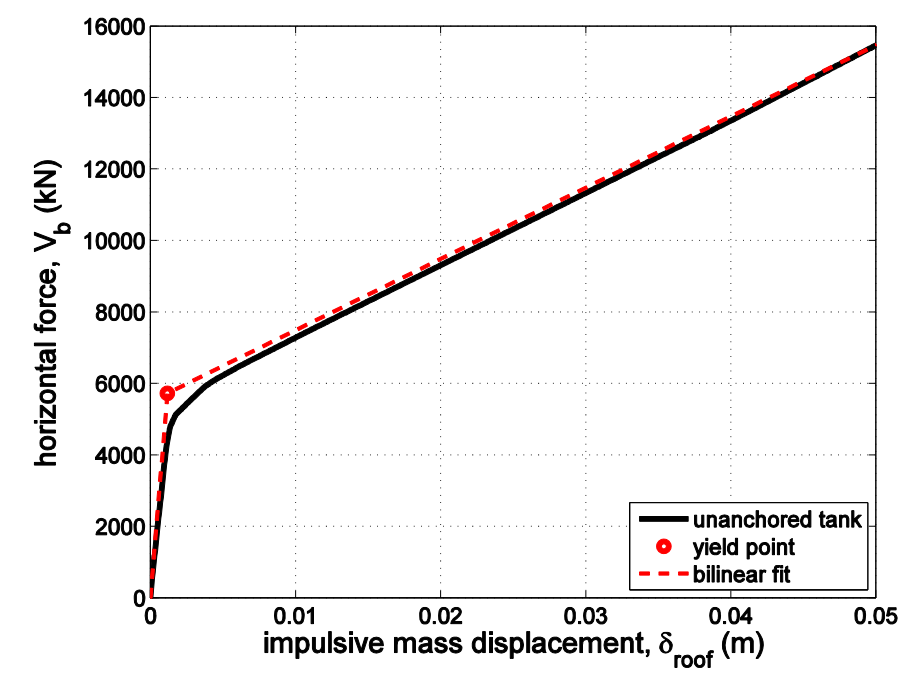

Figure 8: Pushover curve and bilinear fit for the unanchored tank examined.

Converting the damage state capacities outlined above to $\delta_{\text {roof }}$ terms constitutes a very simple task due to the direct mapping offered through the pushover analysis. For the case of plastic rotation, the estimation is fairly obvious due to the underlying correlation with uplift. On the contrary, EFB capacity is slightly trickier to estimate, as according to Eurocode 8 [13], the buckling stress $\sigma_{m}$ is not only a function of the tank wall thickness but also of the internal pressure $(p)$ acting on the walls in the seismic design situation (see Eq. (3)-(5)). The internal pressure is nothing more but the direct sum of the hydrostatic and hydrodynamic (i.e. impulsive) components. The latter involves the impulsive mass acceleration response $(A)$ as shown in Eq. (6), which implies that the inelastic fundamental spectral acceleration should be used instead of the corresponding elastic one.

$$
\begin{gathered}
\sigma_{m}=\sigma_{c 1}\left[1-\left(\frac{p R}{t_{w} f_{y}}\right)^{2}\right]\left(1-\frac{1}{1.12+r^{1.15}}\right)\left[\frac{r+f_{y} / 250}{r+1}\right] \\
\sigma_{c 1}=0.6 E \frac{t_{w}}{R} \\
r=\frac{R / t_{w}}{400} \\
p_{i}(\xi, \zeta, \theta, t)=C_{i}(\xi, \zeta) \rho H \cos \theta A(t)
\end{gathered}
$$


The bilinear approximation adopted allows decoupling of the elastic and inelastic regions, when the corresponding stiffness $\left(k_{e l}, k_{h}\right)$ is considered. Simply put, at the time of maximum deformation, the inertia force equals the maximum spring restoring force. If we let $S_{a}{ }^{e l}$ and $S_{a}^{\text {inel }}$ denote the absolute spectral accelerations in elasticity and inelasticity, respectively, and $S_{d}{ }^{e l}$, $S_{d}^{\text {inel }}$ stand for the corresponding spectral displacements, then, equilibrium for an elastic system would be expressed as:

$$
k_{e l} S_{d}^{e l}=m S_{a}^{e l}
$$

leading to the well-known expression $S_{a}{ }^{e l}=\omega^{2} \cdot S_{d}{ }^{e l}$. Instead, the equilibrium of an inelastic system would appear as

$$
\begin{aligned}
& m S_{a}^{\text {inel }}=k_{e l} \delta_{y}+k_{h}\left(S_{d}^{\text {inel }}-\delta_{y}\right) \Leftrightarrow \cdots \Leftrightarrow \\
& S_{a}^{\text {inel }}=\omega^{2}\left[\delta_{y}\left(1-a_{h}\right)+a_{h} S_{d}^{\text {inel }}\right]
\end{aligned}
$$

that allows us to conveniently use the impulsive mass displacement (available from a pushover analysis) to estimate the corresponding inelastic spectral acceleration that influences EFB failure. As far as sloshing damage is concerned, one may rush into the conclusion that an accurate seismic fragility estimation is not possible using pushover analysis, due to the inherent decoupling between the impulsive and convective response. From a first point of view, this is a valid comment as the pushover analysis fundamentally refers to the first-mode loading pattern only. However, in view of providing an approximate solution for the derivation of fragility curves, the median convective spectral acceleration $S_{a}\left(T_{c o n}, 0.5 \%\right)$ may be converted to $S_{a}\left(T_{i m p}, 2 \%\right)$ terms in order to allow for the corresponding limiting $\delta_{\text {roof }}$ displacement estimation. In our case, the FEMA P695 far-field ground motion set [18] was used to derive the relationship between the central (i.e. median) value of the impulsive and convective spectral accelerations. Although one may follow the scaling procedure for a given set of records shown in Figure 9, in practice the design spectrum could also be employed with the aid of a damping adjustment factor. Care should be exercised though for long convective periods (i.e. $T_{c o n}>4 \mathrm{sec}$ ), as the spectral acceleration shape is not adequately captured through the corresponding design (uniform hazard) spectrum, something that can also be said for accelerograms that have been excessively highpass filtered.

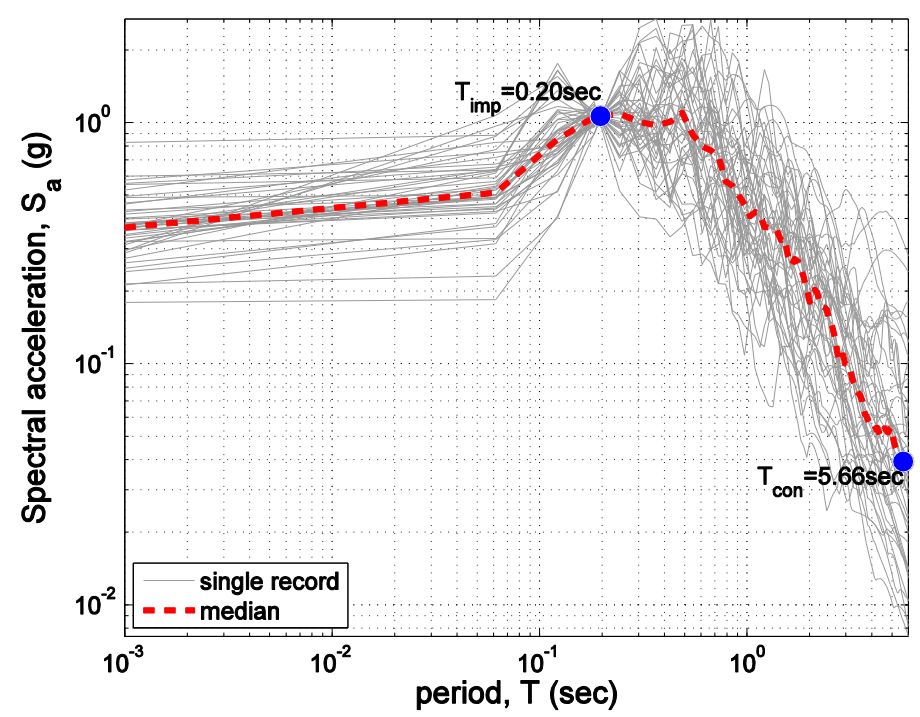

Figure 9: Single record and median spectra featuring the impulsive versus the convective component. 
With the limiting capacities defined, the associated impulsive spectral accelerations may be estimated by inverting the well-known control node displacement response equation found in FEMA 440 [23] (see Eq. (10)). The inelastic displacement ratio $C_{R}$ (also noted as $C_{l}$ in FEMA 440) can be estimated though Eq. (9), where the limiting reduction factor is known from the linear regression equation, for a given ductility. Unlike the majority of static pushover applications, the fundamental-mode participation factor $\left(C_{0}\right)$ is set equal to one, as the capacity curve shown in Figure 8 is a product of a simple SDOF model. Similarly, the stiffness degradation modifier $\left(C_{2}\right)$ is also equal to one due to the nonlinear elastic response of the liquid storage system.

$$
\begin{gathered}
C_{R}^{\lim }=\frac{\mu_{\lim }}{R_{\lim }} \\
S_{a}^{\lim }=\delta_{\text {roof }}^{\lim }\left(\frac{2 \pi}{\mathrm{T}}\right)^{2} \frac{1}{C_{R}^{\lim }} \frac{1}{C_{0}} \frac{1}{C_{2}}
\end{gathered}
$$

The seismic fragility estimation forms a very simple procedure within a probabilistic framework, where the capacities are considered lognormally distributed around the corresponding limiting median estimates. The probability that demand exceeds the median limit state capacity, for a given earthquake intensity, may be calculated through the standard normal cumulative distribution function $\Phi$ shown in Eq. (11). Following a power law approximation for the median demand (valid for performance levels away from the global instability region) [24], the latter can also be given in the form of Eq. (12), where $\beta_{\delta_{\text {roof }}^{\text {lim }}}^{2}$ and $\beta_{\mu}^{2}$ are the median capacity and demand dispersions, and $b$ the slope corresponding to the power law equation (see Eq. (13)). The FEMA P-58 [25] guidelines are recommended for the median capacity dispersion estimation. The proposed strength (EFB), ductility (plastic rotation) and displacement-based (sloshing) procedures are employed for the damage state dispersion estimation. Obviously, for the case that relevant data is available, the corresponding dispersion should be used in view of providing a rather smaller margin of error in the final fragility estimation. Demand dispersion on the other hand should be calculated through the $16 \%$ and $84 \% R-\mu$ fractiles, as shown in Eq. (14).

$$
\begin{gathered}
P\left(C<D \mid S_{a}\right)=\Phi\left(\frac{\ln \hat{\delta}_{\text {roof }}\left(S_{a}\right)-\ln \hat{\delta}_{\text {roof }}^{\lim }}{\sqrt{\beta_{\delta_{\text {roof }}^{\lim }}^{2}+\beta_{\mu}^{2}}}\right) \\
P\left(C<D \mid S_{a}\right)=\Phi\left(\frac{\ln \hat{S}_{a}-\ln \hat{S}_{a}^{\lim }}{\frac{1}{b} \sqrt{\beta_{\delta_{\text {roof }}^{\lim }}^{2}+\beta_{\mu}^{2}}}\right) \\
b=\frac{\ln \mu_{\lim }}{\ln R_{\lim }} \\
\beta_{\mu}=\frac{\ln \mu_{84}\left(R_{\lim }\right)-\ln \mu_{16}\left(R_{\lim }\right)}{2}
\end{gathered}
$$


In order to accurately assess the seismic risk involved in liquid storage tanks, an intensity measure that characterises the structural system's response in an optimal manner must be identified. There could be a lot of discussion regarding which intensity measure better represents the structural response during the seismic risk assessment procedure. Unfortunately, such a discussion is not valid when the pushover analysis is used, as the fundamental-mode loadpattern adopted mandates the use of the corresponding spectral acceleration. For the case of liquid storage tanks that would be the impulsive mass spectral acceleration $S_{a}\left(T_{i m p}\right)$.

Figure 10 presents the seismic fragility evaluation based on the simplified procedure outlined above. Fragility curves are provided for all local damage states given in Table 2, and a comparison with the IDA-based assessment procedure discussed by Bakalis et al. [16] is performed in view of evaluating the proposed SPO-based methodology. It appears that fragility curves are in good agreement for the sloshing and plastic rotation damage states, although minor discrepancies exist throughout the intensity considered, that can be attributed to the fitting procedure of the cumulative distribution function. The Elephant's Foot Buckling failure mode also presents a good match for low to moderate seismic intensities. Discrepancies are noticed though as the impulsive spectral acceleration is increased, where the response seems to be significantly overestimated when the pushover analysis is employed. Although further research is necessary to verify the results of Figure 10, the complexity of the EFB mode of failure as well as the associated uncertainties is of an extent that cannot probably be captured through a SDOF model pushover analysis. Still the seismic fragility product presents a rather conservative illustration of the system's performance, and hence its application within a code-based methodology could be considered.

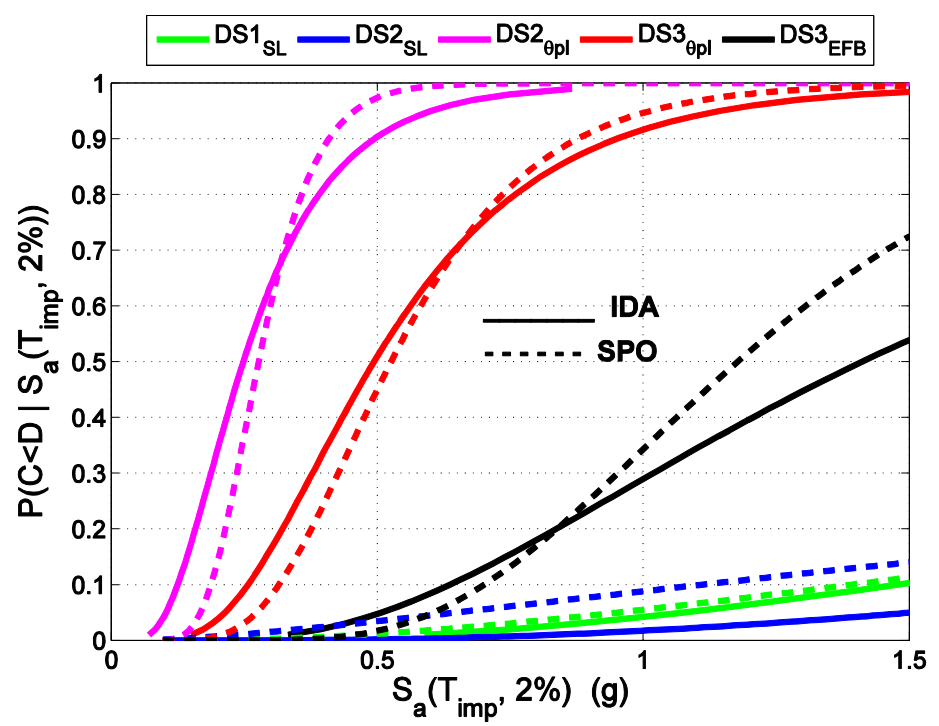

Figure 10: A comparison between IDA and SPO-based fragility curves for the local DS classification.

\section{CONCLUSIONS}

A surrogate, yet robust, beam element model has been presented for the analysis of liquid storage tanks. Its accuracy in comparison with computationally expensive finite element models make it appealing for design applications. Since the computational effort for a single nonlinear response history analysis does not exceed a few seconds, one may realise that the applicability of the SDOF model can be extended to a seismic risk assessment framework. Incremental Dynamic Analysis is employed for the identification of the most damaging failure modes. Local as well as global damage states are defined, favouring the seismic risk assessment of either a 
single liquid storage system or an entire group of tanks, respectively. Following the damage state definition, a simplified assessment methodology is presented based on static pushover analysis, where the estimation of the corresponding limiting capacities is discussed in detail. The evaluation of the pushover-based seismic risk assessment methodology is performed through the extraction of fragility curves that correspond to all local damage states. The comparison with an IDA-based methodology shows the pushover to offer a conservative estimate for the Elephant's Foot Buckling damage state, but a reasonable agreement for the remaining failure modes. The proposed assessment methodology is not intended to substitute well-tested procedures based on nonlinear dynamic analysis. Instead, it attempts to form a simplified technique that may serve under a code-based framework the majority of practicing engineers.

\section{REFERENCES}

[1] Kilic S and Ozdemir Z. "Simulation of Sloshing Effects in Cylindrical Containers under Seismic Loading." Proceedings of the 6 LS-DYNA Anwenderforum, Frankenthal, 2007.

[2] Vathi M, Pappa P and Karamanos SA. "Seismic Response of Unanchored Liquid Storage Tanks." Proceedings of the ASME 2013 Pressure Vessels \& Piping Division Conference, Paris, France, 2013.

[3] Talaslidis DG, Manolis GD, Paraskevopoulos E, Panagiotopoulos C, Pelekasis N and Tsamopoulos J. "Risk analysis of industrial structures under extreme transient loads." Soil Dynamics and Earthquake Engineering, Vol. 24, No.6, 2004, pp. 435-48.

[4] Malhotra PK and Veletsos AS. "Beam Model for Base- Uplifting Analysis of Cylindrical Tanks.” Journal of Structural Engineering, Vol. 120, No.12, 1994, pp. 347188.

[5] Malhotra PK and Veletsos AS. "Uplifting Analysis of Base Plates in Cylindrical Tanks." Journal of Structural Engineering, Vol. 120, No.12, 1994, pp. 3489-505.

[6] Malhotra PK and Veletsos AS. "Uplifting Response of Unanchored Liquid- Storage Tanks.” Journal of Structural Engineering, Vol. 120, No.12, 1994, pp. 3525-47.

[7] Cortes G, Prinz GS, Nussbaumer A and Koller MG. "Cyclic Demand at the Shell-Bottom Connection of Unanchored Steel Tanks." 15th World Conference on Earthquake Engineering, Lisboa, Portugal, 2012.

[8] NZEE. "Seismic Design of Storage Tanks." New Zealand National Society for Earthquake Engineering Wellington, New Zealand, 2009.

[9] Malhotra PK, Wenk T and Wieland M. "Simple Procedure for Seismic Analysis of Liquid-Storage Tanks.” Structural Engineering International, Vol. 10, No.3, 2000, pp. 197-201.

[10] Priestley MJN, Wood JH and Davidson BJ. "Seismic Design of Storage Tanks." Bulletin of the New Zealand Society for Earthquake Engineering, Vol. 19, No.4, 1986, pp. 272 84.

[11] Calvi GM and Nascimbene R. "Progettazione sismica dei serbatoi." Progettare i gusci, IUSS Press, 2011. p. 537-672.

[12] CEN. "Eurocode 8: Design Provisions Of Structures For Earthquake Resistance - Part 1: General rules, seismic actions and rules for buildings, CEN, Brussels." CEN [Comité Européen de Normalisation], 2004.

[13] CEN. "Eurocode 8: Design of structures for earthquake resistance-Part 4: Silos, tanks and pipelines." European Committee for Standard. Brussels, 2006.

[14] Malhotra PK. "Seismic Response of Soil-Supported Unanchored Liquid-Storage Tanks." Journal of Structural Engineering, Vol. 123, No.4, 1997, pp. 440-50. 
[15] Bakalis K, Vamvatsikos D and Fragiadakis M. "Surrogate Modelling and Sensitivity Analysis of Steel Liquid Storage Tanks." 8th Hellenic National Conference of Steel Structures, Tripoli, Greece, 2-4 October 2014, 2014.

[16] Bakalis K, Vamvatsikos D and Fragiadakis M. "Seismic Reliability Assessment of Liquid Storage Tanks." 2nd European Conference on Earthquake Engineering and Seismology, Istanbul, Turkey, 24-29 August 2014, 2014.

[17] Vamvatsikos D and Cornell CA. "Incremental dynamic analysis." Earthquake Engineering \& Structural Dynamics, Vol. 31, No.3, 2002, pp. 491-514.

[18] FEMA. "Quantification of Building Seismic Performance Factors." FEMA P-695, prepared by Applied Technology Council for Federal Emergency Management Agency, Washington, D.C., 2009.

[19] Veletsos A and Newmark NM. "Effect of inelastic behavior on the response of simple systems to earthquake motions." Proceedings of the 2nd World Conference on Earthquake Engineering, 1960. p. 895-912.

[20] Vamvatsikos D and Cornell CA. "Direct estimation of the seismic demand and capacity of oscillators with multi-linear static pushovers through IDA." Earthquake Engineering and Structural Dynamics, Vol. 35, No.April 2004, 2006, pp. 1097-117.

[21] Ruiz-García J and Miranda E. "Probabilistic estimation of maximum inelastic displacement demands for performance-based design." Earthquake Engineering and Structural Dynamics, Vol. 36, No.March, 2007, pp. 1235-54.

[22] Kreslin M and Fajfar P. "The extended N2 method taking into account higher mode effects in elevation." Earthquake Engineering and Structural Dynamics, Vol. 40, 2011, pp. 1571-89.

[23] FEMA. "Improvement of Nonlinear Static Seismic Analysis Procedures." FEMA 440, prepared by the Applied Technology Council for the Federal Emergency Management Agency, Washington D.C, 2005.

[24] Cornell CA, Jalayer F, Hamburger RO and Foutch D a. "Probabilistic Basis for 2000 SAC Federal Emergency Management Agency Steel Moment Frame Guidelines." Journal of Structural Engineering. 2002. p. 526-33.

[25] FEMA. "Seismic Performance Assessment of Buildings." FEMA P-58, prepared by the Applied Technology Council for the Federal Emergency Management Agency, Washington D.C, 2012. 